\title{
Mobile Payments-Why They Are So Successful?
}

\author{
Lu Lu \\ Nanjing Normal University, Nanjing, China \\ Email:lulu_altai@yahoo.com
}

How to cite this paper: Lu, L. (2019) Mobile Payments-Why They Are So Successful? Open Journal of Business and Management, 7, 1131-1143.

https://doi.org/10.4236/ojbm.2019.73078

Received: April 20, 2019

Accepted: May 14, 2019

Published: May 17, 2019

Copyright $\odot 2019$ by author(s) and Scientific Research Publishing Inc. This work is licensed under the Creative Commons Attribution International License (CC BY 4.0).

http://creativecommons.org/licenses/by/4.0/

\begin{abstract}
Mobile payment service is exploding at an impressive rate as the global mobile payment revenue almost tripled over the last five years. But the reasons behind this phenomenon are still not clear. This paper thus focuses on identifying the key factors that contribute to the success of mobile payments. We firstly take a look at the current status of mobile payments. With this brief background in mind, we then address several questions associated with three key actors of mobile payment ecosystem: m-payment service provider, consumer, merchants. Specifically, the business model of mobile payments firms (including value proposition, market contribution, revenue source), consumer preferences and merchant. Conclusions: Mobile payment is gradually developing towards diversification and cross-border integration with highly sophisticated technology behind; the success of mobile payments application is based on aprofitable and valuable business model; in order to gain a competitive advantage when facing with fierce competition in the market, firms should respond best to consumer change and merchant feedback.
\end{abstract}

\section{Keywords}

Mobile Payments, Business Model, Consumer Preference, Merchants Power

\section{Introduction}

If smartphones could be considered as the first generation of revolution to change the way people lead daily life. The rise in global popularity of mobile payments would definitely be the second one. A mobile payment or m-payment is any payment where a mobile device is used to initiate, authorize and confirm an exchange of financial value in return for goods and services [1]. As digital wallets become more prevalent, it is surprising that the global market is exploding at an impressive rate, especially in developing countries like China and India. 
Mobile payment transactions in China alone added up to more than 15 billion for the $2^{\text {nd }}$ quarter of year 2018 compared to 2 billion three years ago [2]. The adoption of mobile payments in developed countries like Canada and America is relatively slow but still increasing steadily. At this point of development, we are going to take a look at the current state of the mobile payments as well as the reasons that make mobile payments playing such a key role in payment market.

The importance of the work could be identified as two aspects. Academically, compared with the rapid growth of mobile payments in real world, so far the academic research within the aspects of mobile payments' competitive advantage in the market level is apparently lagging behind. To clarify the economic logic behind this trendy phenomenon would not only provide a more comprehensive understanding of the success of mobile payments, but would also fill the research gap. Practically, for the firms who are leading the business associated with mobile payments, a better understanding of the reasons why and how could mobile payments to be such a success would identify new solutions when facing the fierce competition. Also, potential opportunities would be recognized to help firms gain a competitive advantage among the industry.

This paper might add to existing studies on mobile payments from the prospective of market level. On the one hand, particular topics on the success mechanism of mobile payments are urgently needed among academics. On the other hand, based on mobile payment ecosystem, explaining the characteristics through three key parties of mobile payments services is an objectively and rationally way to recognize the market phenomenon in real world.

The article is question-driven organized, as shown in Figure 1, the questions we plan to address in this paper are associated with three key parties of mobile payment ecosystems (i.e. m-payment service provider, consumer, merchants). Business is all about competition. As Michael Porter explained, profitability comes from gaining competition advantage [3]. Thus the analyze is mainly based on the perspective of the fierce competition in market. What is the business model of mobile payments? How could consumer choices drive the development of mobile payment services market? Why merchants are on a dominant position adopting mobile payments? Meanwhile, the analysis would be taken under the assumption of homo economicus, in other words, economic man [4]. Unlike a real human, economic man always behaves rationally in a narrowly self-interested way that maximizes his or her satisfaction. For future research, some econometrical methods should be used to enhance the credibility of the results.

\section{Literature Review}

How success is mobile payment? With the increasing affordability of mobile payment Apps, almost every kind of mobile commerce purchase or transaction could be paid through the mobile device. Even in many physical stores, mobile devices can also be used as payment method. Figure 2 shows the global mobile payment annual transaction volume from 2015 to 2019 [5]. The worldwide mo- 
bile payment transaction volume in 2015 was 450 billion US dollars and is expected to surpass 1 trillion US dollars in 2019. As can be seen, the transaction volume almost tripled within five years.

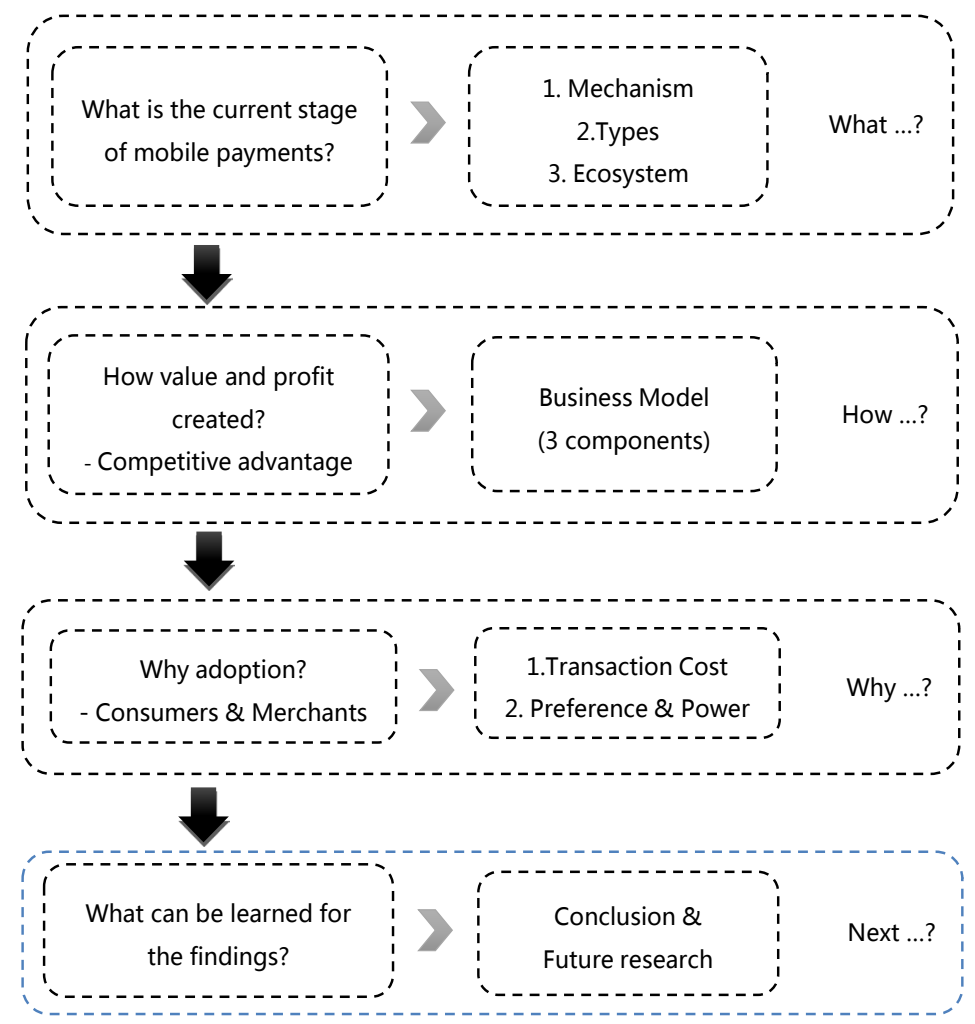

Figure 1. Structureof the research.

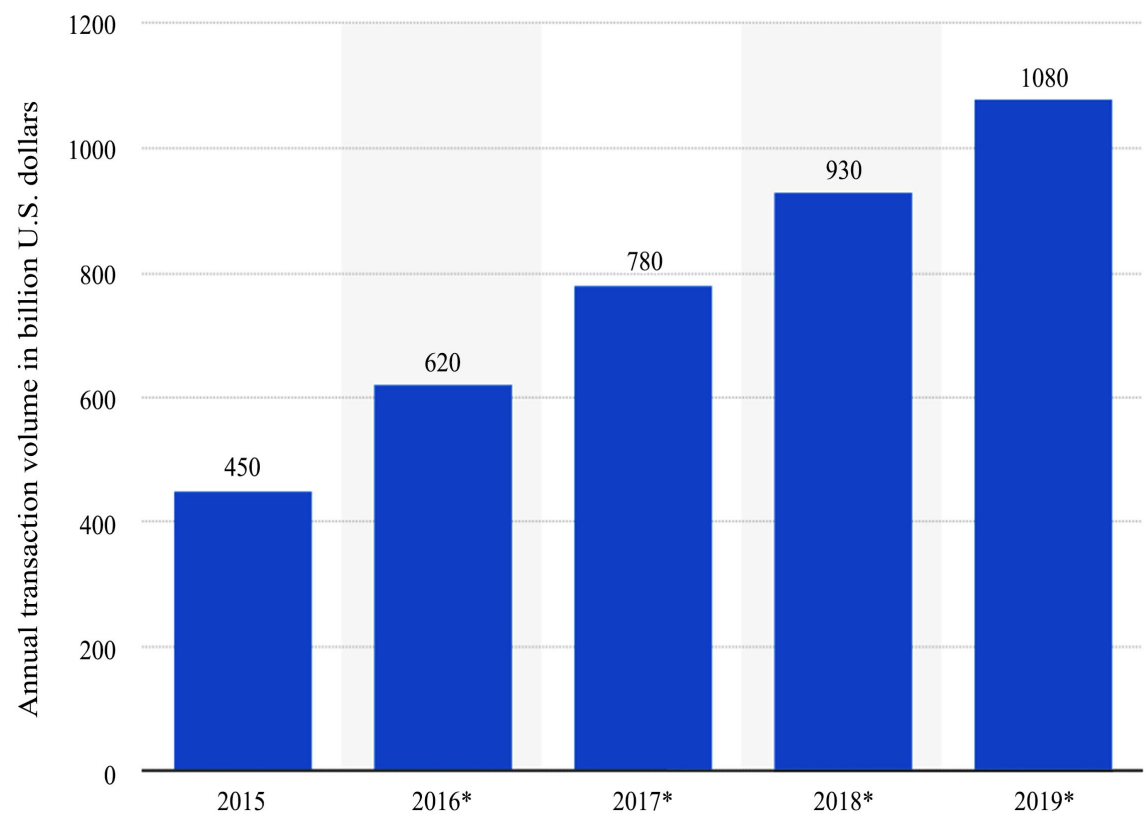

Figure 2. Total revenue of global mobile payment market from 2015 to 2019 (in billion US dollars). 
Mobile payments refer to any payment made using a mobile device [1] [6] [7]. Since there is no physical contact between the device and the payments reader, mobile payments are often referred to as contactless payments. Mobile payments turned mobile devices (smartphone, ipad, etc.) into micro-wallet which contains at least one mobile financial applications such as TD Canada App, Apple Pay, Samsung Pay, Ali Pay, WeChat Pay, etc. Due to the development technology, smartphones have financial functions but doing more with less.

Users can make a mobile payment in a number of different ways [8]. Users may use their mobile phones to pay for buses, utilities, hotels, food delivery, car washes, gasoline, even soft drinks from vending machines [9]. Mobile payments, as all other payments, fall broadly into two categories: payments for daily purchases, and payments of bills (credited payments) [6]. A person can also use his or her mobile phone to make online purchases through a merchant's website or through their wireless provider.

Although the concept of business model is widely used and seen as important, there is no generally accepted definition of what a business model is. In academic, it can be classified as two taxonomies: broad definition and narrow definition.

For the broad definition, it is a design for the successful operation of a business, identifying revenue sources, customer base, products, and details of financing. A business model describes the logic of a "business system" for creating value that lies behind the actual processes [10]. It can be seen as a detailed conceptualization of an enterprise's strategy at an abstract level [11], which serves as a base for the implementation of business processes.

For the narrow definition, a business model provides a description of the roles and relationships of a company, its customer, partners and suppliers, as well as the flows of goods, information and money between these parties and the main benefits for those involved, in particular, but not exclusively the customer [12] [13] [14].

Key components of the basic payment ecosystem would be recognized with the "Three-party Scheme", i.e. the merchant, the customer, the service provider. Most payments compete in two-sided markets where different costumer groups-payers and payees-are matched through some means of digital intermediation [15] [16] [17]. Thus, the dynamics of payment markets are similar to mobile industries and characterized by tension between merchants and consumer as well as the service provider. They arguably are the most important stakeholders for the success of m-payments in the marketplace [18].

This paper thus focuses on the basic ecosystem of a mobile payment in the market level which contains three parties mainly, i.e. the tech-firms, consumer and merchant (see Figure 3). They are the key stakeholders in mobile payments ecosystem. Understanding how these three factors contribute to the popularity and success of mobile payments is the mainly purpose in this paper. The rest of the paper are structured as follows. First, we identify the business model of mobile payments firms. Second, we discuss how consumer behavior, or consumer 


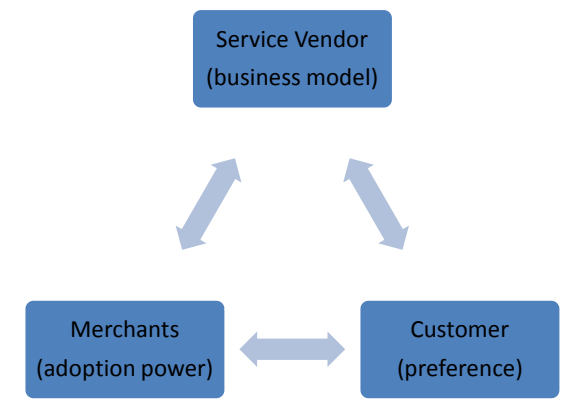

Figure 3. Mobile payments ecosystem in market level.

prefer contributed to the adoption of mobile payments. Third, we introduce the concept of transaction cost to analyze the impacts of merchants' power.

\section{Business Model}

As explained by Yuan (2003), business models have two dimensions: the key components and the taxonomy. Here, the key components include the scope, the value propositions, the revenue sources, and the roles of a value chain [19]. In this section, we will focus on the principal components of the business models of the mobile payments from the market perspective. In the market level, we take both of the supply side (service provider) and demand side (service user) into consideration, to identify how mobile payments gain competitive advantage among the payments market. Thus, we use business models overview to analysis three questions:

1) What features make it attractive? - Value proposition.

2) What benefits can it bring to market?-Market contribution.

3) How to profit from it?-Revenue source.

\subsection{Value Proposition}

Convenience: Mobile payment Apps all have one thing in common; they bring a certain degree of convenience in the services they offer, including money transfer and payments. These Apps streamline that by enabling one person to pay with a credit card and everyone else to pitch in via an App. It actually is allowing these services to build a large user volume. A very huge part of the population own smartphones hence by using mobile payment Apps, the service providers have brought the services closer to the people. This type of convenience is one of the major factors that has made mobile payment Apps so popular.

There are a host of payment Apps that allow users to easily move money to other individuals without the hassle of cash. This is perfect for when you're out with a group of friends and struggling to split the bill. These payment Apps save time as most of the transactions are instant, and reflect on the recipients' accounts almost immediately, regardless of how far they are. All these could happen at the tip of fingertips of the user.

Technology: Mobile payment industry belongs to emerging industries as the cutting-edge technology is one of the key components of mobile payments. The 
technology behind mobile payments continues to improve at a rapid pace. It can be throughout the whole process of the mobile payments chain. Since this paper is focused on the market level, we are not going through details about the highly sophisticated technology behind the service. In terms of the function, seamless user interface design is one thing to have an App with high popularity among the masses.

A seamless user-interface design is mandatory to make a mobile payment with high usage. Meanwhile, it is the key factor to be able to attract and to keep a high retention rate. Since internet-industry is mainly about the competition to gain and retain active user. Especially in the attention economy, user's attention is shifting quickly and irregularly. Firms would lose their users if their user interface is not attractive and simple enough. Mobile payment Apps' user interface is designed in such a way that it is very attractive, easy to follow through and very simple. Ease of carrying out transactions ensure high usability of App such as PayPal and Google pay.

Integration: App products are developing fast and diverse more than just a financial App. These services could turn a mobile device into a business tool, replacing bank, ATM, and credit cards by letting a user conduct financial transactions with mobile money [20]. One interesting mobile financial application is micro-payment involving social media applications such as WeChat-a Chinese multi-purpose messaging, social media and mobile payment App developed by Tencent ${ }^{1}$. It was first released in 2011 [21], and by 2018 it was one of the world's largest standalone mobile Apps by monthly active users [22]. WeChat Pay is a digital wallet service incorporated into $\mathrm{WeChat}$, which allows users to perform mobile payments and send money between contacts.

It accumulated great numbers of users through its chatting platform which make it much easier for users to make further financial activities. The diversified integration across multiple functions and platforms ensures user friendliness and some sort of variety for the clients and this should be the target of each and every App developer where applicable.

Cost saving: One of the factors explaining the pace of innovation is that payment fees, even though the fees are declining per transaction, still are among the most important sources of revenues for banks [20]. Most person-to-person payments are free with these Apps, unless using a credit card rather than a bank account or debit card. Some services charge yet another fee when users want to transfer received money to their bank account. For example, WeChat charges additional service fee for withdrawal balance to the bank account with fee rate of $0.01 \%$, Square Cash charges one percent for this if the owner enables its auto-deposit feature, and Venmo charges 25 cents per expedited deposit. Thus, mobile payment has become a favorite among customers and merchants due to its cheaper transaction cost compared to cards. As we discuss next, the transac-

${ }^{1}$ Tencent Holdings Limited is a Chinese multinational investment holding conglomerate founded in 1998, whose subsidiaries specialize in various Internet-related services and products, entertainment, artificial intelligence and technology both in China and globally. 
tion cost is the core factor that contributes the adoption of mobile payments by consumers and merchants.

Safety: Mobile payment Apps make it more secure for the clients to carry out transactions, instead of the alternative of carrying cash or debit and credit cards which for a long time have had issues with encryption flaws. Payment information during the transaction process is usually encrypted and is thought to be a significantly safer method of making payments compared to cards. Therefore, information can only be viewed by three parties: the user, the bank and the App. Each time a transaction made, the phone sends two pieces of information to the payment station, a one-time code generated by that phone's encryption key and a 16-digit code of the card. This lets the transaction to be as private as possible. If people lost their phones, it can erase this information remotely. Biometric authentication technology checks physical metrics to recognize and verify a person. This technology can recognize a person's voice, typing rhythm, and even gestures. Yet many other characteristics can be used too. But yes, it has a very high level of security.

\subsection{Market Contribution}

E-commerce: Market contribution is all about the benefits that mobile payments can bring to the market. Specifically, as a fundamental element of mobile commerce, mobile payments play an essential role to boost the performance and to contribute to the development of mobile commerce. Mobile commerce is the process of e-commerce with the adoption of smartphone applications benefit from emerging wireless and mobile network [20]. It has profound influences on certain industries like financial services (e.g. crowd funding, virtual currency), retails and groceries (e.g. mobile coupons, online purchases), entertainments (e.g. movies, music), sharing economies (e.g. carpool, real estate), even for industries like gas stations have been affected quite a lot.

Figure 4 shows the transaction value of global $\mathrm{m}$-commerce sales rose from $\$ 50$ billion in 2014 to almost $\$ 300$ billion in 2017 [23]. For 2019, Statista, a German online portal for statistics, predicts revenue of almost $\$ 700$ billion. Based on this volume of transaction, the contribution that mobile payments can make to the market is gradually expanding.

\subsection{Revenue Source}

A successful business should have profitability. The question is how would a company or a vendor make any profit on mobile payments? A critical part of business model analysis is the determination of the sources of revenues [24]. The different revenue sources can be categorized as consumers, merchants, and third parties [25]. In addition, different revenue types can be distinguished as transaction depended or transaction un-depended [26]. The former is related to revenues that are generated based on each transaction. The latter depicts revenues that are not tied to the transaction volumes, they might not occur regularly at least for a certain period. 
Table 1 shows the main sources of revenue to mobile payments vender. For each party in the mobile payment ecosystem, we separate two categories to identify the revenue source, i.e. transaction depended and transaction un-depended.

For the revenue streams from consumer, service providers could require pre-payments by users for download and installment of mobile payment applications, thereby leading to some financial profits like Softcard. Value-added service like the Stickers Gallery in WeChat Pay; users have to pay for the stickers which would be used in the ubiquitous communication. Some mobile payments also have entertainments embedded in applications, like mini-games. They are usually free at the beginning but it will need to pay in future, which is a marketing strategy that keeps the user active. The sources related to transaction dependent are mainly about the money that in the mobile wallet account, such as balance withdrawal, e-transfer, credit card repay. Cost of micro-payments may decrease with increased numbers of transactions or users; thus the revenue would still keep running.

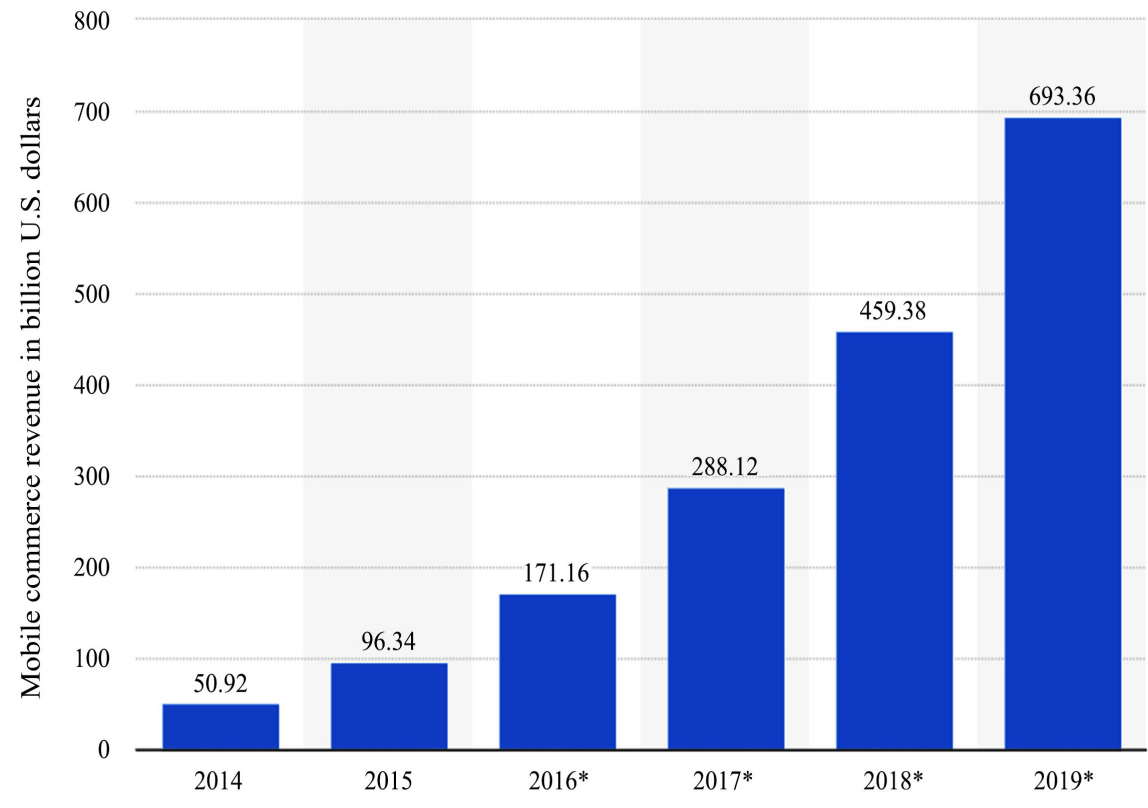

Figure 4. Transaction value of global m-commerce sales from 2014 to 2019 (in billion US dollars).

Table 1. Sources of revenue from three parties to the service provider.

\begin{tabular}{llll}
\hline \multicolumn{2}{c}{ Consumer } & Merchants & Third-parties \\
\hline & $>$ Download/Installment/Use & $>$ Account opening & $>$ Advertising \\
Transaction & of mobile payment App (App & $>$ Rental fee (POS) & $>$ Platform integration \\
un-depended & Store) & $>$ Multi-financial \\
& $>$ Value added services (Stickers) & $>$ Backround & services (data \\
& $>$ Entertainment & operation maintains & outsourcing) \\
& $>$ Additional service fee (Balance & $>$ Transaction & $>$ Banks-transaction \\
Transaction & withdraw) & $>$ Additional service fee & $>$ License M\&A \\
depended & $>$ E-transfer & (promotion) & $>$ Multi-financial \\
& $>$ Card repay & $>$ Coupon/Gift cards & services (investment)
\end{tabular}


For the revenue streams from merchants, un-depended transaction revenue including account opening fee (similar with the download/installment fee for customer), rental fee (POS), background operation maintains (mobile operators also have an opportunity to obtain revenue from increased network use [27]). Merchants that are used to accepting cash only will now have to consider giving up some of their revenues (a relatively small portion) to the providers as $\mathrm{m}$-payment service fees, for the $\mathrm{m}$-payment services providers will surely not offer free payment services for very long. Take google as an example, the main revenue driver will be Google Offers, in which merchants will be charged when they place customized promotion ads and coupons to consumers through the mobile wallet.

For the revenue streams from third-parties, they are playing big proportion of revenue resources. In the advertising revenue model of mobile payments, it permits advertisers to list their ads on applications/websites and in turn the vendor charge them lump sum or annual subscription. As such Google provide most of its services free of charge for consumers, merchants, and banks. It clearly shows that Google is only interested in ad revenues [26], i.e. incremental revenues generated from targeted offers, loyalty programs and digital downloads, rather than taking a share of current card payments revenues. There can be overlaps between platform integration and license acquirement as they will not happen quite often. Once one of them is launched, it will bring a huge revenue to the vendor. Stakeholders in the ecosystem that control important resources (license) can exercise power over other stakeholders and can capture a larger part of the ecosystem's total revenues [28]. Data outsourcing means sharing/selling the data of user's behavior history. For example, commercial banks could use these date to identify potential customers within a certain distance from a geographic location. What's more, user can place an investment order if they have an investment account for a financial purpose.

A provider can also charge a small amount for the payment service or can absorb the cost in order to provide the micro-payment as a competitive feature leading to an increased number of users and possibly higher revenues. Here users refer to both side of consumers and merchants, as long as they have smartphone (or any other mobile devices) and the service is supported on that device.

\section{Consumer Preferences}

This section is focused on one question: what customers really want? From a technology adoption cycle perspective [29], the firm targets the consumer mass-market users, who are typically interested by convenience and low prices. These two factors play decisive role in consumer preferences.

For each individual customer, convenience comes priority. Besides the basic function of mobile payment instead of cash and cards, convenience could also be easily recognized from diverse functions and multiple financial services. Take Ali Pay as an example, it has an extra function called "My Package" embedded in 
the payment App. That function makes it quite easy for users to track their package, order or even return back a delivery in real would. In addition, this kind of strategy allows for a seamless experience between online and offline, easily allowing customers to make purchases with their phones and redeem those purchases offline.

Low prices requirement could be identified from financial services. It is easily for users to manage their e-wallet money through those mobile payment Apps. Money in the WeChat wallet can be invested for P2P funds to earn yields without cost that physical finance company would charge, such as opening account fee, consultant fee. Meanwhile, the money that has been invested into funds can be withdraw and spend at any time. But for physical finance institution, at least 1 - 3 business days should be delayed. Besides, repeat payments can be made faster if users have already sent money to a friend or family member, they can tap on a previous transaction and send money again without entering any recipient data. Undoubtedly, these services could easily meet consumer's convenience requirement as well as low prices requirement at the same time.

\section{Merchants Power}

This section is focused on one question: why merchants are on a dominant position adopting mobile payments? Whether to adopt mobile payment App is, at least in principle, a straightforward cost-saving question. Since merchants do business for profit purpose, any kind of improvement would be accepted as long as it could reduce the cost or boost the profit. According to the transaction costs theory [30], transaction costs generally refer to all the costs incurred to facilitate the occurrence of a transaction. Different transactions often involve different types of transaction costs. Due to technological advances, mobile payments could lower the transaction costs compare to the traditional payments. Narrowly speaking, it will enable merchants to accept payment from a contactless card or mobile wallet using just their phone-essentially turning their smartphone into a payment terminal.

As for the power of merchants, they are having a big impact on mobile payments behaviors and encouraging the transition to mobile devices. Compare to consumer preference variability, merchants are relatively stable and have more market control power. People always ask what type of payments would be available at a particular store, either online or offline, before they purchase. It is the merchant who have the right to decide the way consumer pay, it is the merchant who is standing on dominant position.

Also, when facing the dynamic market environment, instead of focusing on the last mile of the problem-making the payment itself-companies are focusing on loyalty and trying to change the way merchants offer their products to customers. These companies leverage the wealth of data that merchants have about purchase history to craft a unique offer for each customer. Merchants, on the other hand, favor m-payment schemes that are flexible, affordable to implement and help them convert more users, generating volume for their business. 


\section{Conclusions}

It can be seen that mobile payment is gradually developing towards diversification and cross-border integration. As the existing literature has been confirmed, mobile payment does not completely replace physical payment cards, but is likely to substitute for paper-based payment methods such as cash and checks at the adoption stage [31]. As a result, the types of mobile payments would probably go further and turn out more novel design.

The success of mobile payments application is based on an appropriate business model that can lead to real profit, including value proposition, market contribution and revenue source. In addition, service providers' value proposition should focus on user priorities: convenience, simplicity, security, technology, economy. How mobile payments can save time or effort, or how technology can enrich life experiences? addressing these are key to eliciting consumers to embrace mobile payments.

In order to gain a competitive advantage when facing with fierce competition in the market, the winners in mobile payments might not be its strongest or most strategically players, but rather those who respond best to consumer change and merchant feedback. Thus, vendors should pay attention to both industry and market fluctuation.

\section{Conflicts of Interest}

The author declares no conflicts of interest regarding the publication of this paper.

\section{References}

[1] Karnouskos, S. (2004) Mobile Payment: A Journey through Exiting Procedures and Standardization Initiatives. IEEE Communications Surveys and Tutorials, 6, 44-66. https://doi.org/10.1109/COMST.2004.5342298

[2] Payment and Settlement Department of the People's Bank of China (2018) China Payment System Development Report. China Financial Publishing House, Beijing.

[3] Porter, M. (1979) How Competitive Forces Shape Strategy. Harvard Business Review, 57, 137-145.

[4] Smith, A. (1776) The Wealth of Nations. W. Strahan and T. Cadell, London.

[5] “The Statistics Portal”, E-Commerce, Digital Payments, Global Mobile Payment Revenue 2015-2019.

https://www.statista.com/statistics/226530/mobile-payment-transaction-volume-for ecast

[6] Dahlberg, T., Mallat, N., Ondrus, J. and Zmijewska, A. (2008) Past, Present and Future of Mobile Payments Research: A Literature Review. Electronic Commerce Research and Applications, 7, 165-181. https://doi.org/10.1016/j.elerap.2007.02.001

[7] Ozcan, P. and Santos, F.M. (2014) The Market That Never Was: Turf Wars and Failed Alliances in Mobile Payments. Strategic Management Journal, 36, 1486-1512. https://doi.org/10.1002/smj.2292

[8] Sorensen, E. (2018) Different Types of Mobile Payments Explained. Mobile Transaction. https://www.mobiletransaction.org/different-types-of-mobile-payments 
[9] Turban, E., King, D., Lee, J., Warkentin, M. and Chung, H.M. (2002) Electronic Commerce 2002: A Managerial Perspective. Prentice Hall, Upper Saddle River.

[10] Petrovic, O., Kittl, C. and Teksten, R. (2001) Developing Business Models for Ebusiness. International Conference on Electronic Commerce, Vienna, 31 October, 1-6. https://doi.org/10.2139/ssrn.1658505

[11] Camponovo, G. and Pigneur, Y. (2003) Business Model Analysis Applied to Mobile Business. Proceedings of the 5 th International Conference on Enterprise Information Systems, Angers, 22-26 April 2003, 23-26.

[12] Bouwman, H. (2002) The Sense and Nonsense of Business Models. International Workshop on Business Models, Lausanne, 4-5 October, 1-6.

[13] Viscio, A. and Paternack, B.A. (1996) Towards a New Business Model. Strategy + Business, No. 20, Second Quarter. https://www.strategy-business.com/article/14974?gko=d8b48

[14] Lee, I. and Shin, Y.J. (2018) Fintech: Ecosystem, Business Models, Investment Decisions, and Challenges. Business Horizons, 61, 35-46.

https://doi.org/10.1016/j.bushor.2017.09.003

[15] Evans, D.S., Hagiu, A. and Schmalensee, R. (2006) Invisible Engines: How Software Platforms Drive Innovation and Transform Industries. MIT Press, Boston. https://doi.org/10.7551/mitpress/3959.001.0001

[16] Rochet, J.C. and Tirole, J. (2003) Platform Competition in Two-Sided Markets. Journal of the European Economic Association, 1, 990-1029. https://doi.org/10.1162/154247603322493212

[17] Shapiro, C. and Varian, H.R. (2013) Information Rules: A Strategic Guide to the Network Economy. Harvard Business Press, Boston.

[18] Au, Y.A. and Kauffman, R.J. (2008) The Economics of Mobile Payments: Understanding Stakeholder Issues for an Emerging Financial Technology Application. Electronic Commerce Research and Applications, 7, 141-164. https://doi.org/10.1016/j.elerap.2006.12.004

[19] Yuan, Y. and Zhang, J.J. (2003) Towards an Appropriate Business Model for $\mathrm{m}$-Commerce. International Journal of Mobile Communications, 1, 35-56. https://doi.org/10.1504/IJMC.2003.002459

[20] Varshney, U. and Vetter, R. (2002) Mobile Commerce: Framework, Applications and Networking Support. Mobile Networks and Applications, 7, 185-198. https://doi.org/10.1023/A:1014570512129

[21] Alon, I. and Zhang, W. (2009) Biographical Dictionary of New Chinese Entrepreneurs and Business Leaders. Edward Elgar Publishing, Cheltenham, 111-112.

[22] The Economist (2016) WeChat's World.

[23] The Statistics Portal, E-Commerce, Digital Payments, Global Mobile Commerce Transaction Value 2014-2019.

https://www.statista.com/statistics/557951/mobile-commerce-transaction-value-wo rldwide

[24] Afuan, A. and Tucci, L.C. (2001) Internet Business Models and Strategies. McGraw-Hill Higher Education, New York.

[25] Pousttchi, K., Schiessler, M. and Wiedemann, D.G. (2009) Proposing a Comprehensive Framework for Analysis and Engineering of Mobile Payment Business Models. Information Systems and e-Business Management, 7, 363-393. https://doi.org/10.1007/s10257-008-0098-9

[26] Sang Un Chae, J. and Hedman, J. (2015) Business Models for NFC Based Mobile 
Payments. Journal of Business Models, 3, 29-48.

[27] Alliance, S.C. (2007) Proximity Mobile Payments: Leveraging NFC and the Contactless Financial Payments Infrastructure.

[28] Hedman, J. and Henningsson, S. (2015) The New Normal: Market Cooperation in the Mobile Payments Ecosystem. Electronic Commerce Research and Applications, 14, 305-318. https://doi.org/10.1016/j.elerap.2015.03.005

[29] Moore, G. (1999) Crossing the Chasm. Harper Business, New York.

[30] Coase, R. (1937) The Nature of the Firm. Economica, 4, 386-405. https://doi.org/10.2307/2626876

[31] Trütsch, T. (2016) The Impact of Mobile Payment on Payment Choice. Financial Markets and Portfolio Management, 30, 299-336.

https://doi.org/10.1007/s11408-016-0272-x 